\title{
Timescale Analyses of Fluctuations in Coexisting Populations of a Native and Invasive Tree Squirrel
}

\author{
Robert Desharnais ${ }^{1}$, Alan Muchlinski ${ }^{1}$, Janel Ortiz ${ }^{2}$, Ruby Alvidrez ${ }^{1}$, and Brian Gatza ${ }^{1}$ \\ ${ }^{1}$ Cal State LA \\ ${ }^{2}$ Cal Poly Pomona
}

December 3, 2021

\begin{abstract}
1. Competition from invasive species is an increasing threat to biodiversity. In Southern California, the western gray squirrel (Sciurus griseus, WGS) is facing increasing competition from the fox squirrel (Sciurus niger, FS), an invasive congener. 2. We used spectral methods to analyze 140 consecutive monthly censuses of WGS and FS within a 11.3 ha section of the California Botanic Garden. Variation in the numbers for both species and their synchrony was distributed across long timescales ( $>15$ months). 3. After filtering out annual changes, concurrent mean monthly temperatures from nearby Ontario Airport (ONT) yielded a spectrum with a large semiannual peak and significant spectral power at long timescales ( $>30$ months). Squirreltemperature cospectra showed significant negative covariation at long timescales ( $>35$ months) for WGS and smaller significant negative peaks at 6 months for both species. 4. Simulations from a Lotka-Volterra model of two competing species indicates that the risk of extinction for the weaker competitor increases quickly as environmental noise shifts from short to long timescales. 5. We analyzed the timescales of fluctuations in detrended mean annual temperatures for the time period 1915-2014 from 1218 locations across the continental USA. In the last two decades, significant shifts from short timescales to long timescales have occurred, changing from less than 3 years to 4-6 years. 6. Our results indicate that (i) population fluctuations in co-occurring native and invasive tree squirrels are synchronous, occur over long timescales, and may be driven by fluctuations in environmental conditions; (ii) long timescale population fluctuations increase the risk of extinction in competing species, especially for the inferior competitor; and (iii) the timescales of interannual environmental fluctuations may be increasing from recent historical values. These results have broad implications for the impact of climate change on the maintenance of biodiversity.
\end{abstract}

\section{Hosted file}

ECE-2021-Desharnais-et-al.pdf available at https ://authorea.com/users/449210/articles/547780timescale-analyses-of-fluctuations-in-coexisting-populations-of-a-native-and-invasivetree-squirrel

\section{Hosted file}

ECE-2021-Desharnais-et-al_Figures.pdf available at https://authorea.com/users/449210/ articles/547780-timescale-analyses-of-fluctuations-in-coexisting-populations-of-anative-and-invasive-tree-squirrel

\section{Hosted file}

ECE-2021-Desharnais-et-al_Appendix.pdf available at https://authorea.com/users/449210/ articles/547780-timescale-analyses-of-fluctuations-in-coexisting-populations-of-anative-and-invasive-tree-squirrel 